\title{
FORKOME MODEL APPLICATION FOR PROGNOSIS OF FOREST FIRES
}

\author{
IHOR KOZAK ${ }^{1}$, ANDRZEJ WĘGIEL ${ }^{3}$, PAWEŁ STRZELIŃSKI ${ }^{3}$ RAFAŁ FRĄK ${ }^{1}$, ADAM \\ STEPIEN $^{1}$ PIOTR KOCIUBA ${ }^{1}$, HANNA KOZAK ${ }^{2}$
}

\footnotetext{
${ }^{1}$ Department of Landscape Ecology, John Paul II Catholic University in Lublin, Konstantynów 1H, 20-708 Lublin, Poland; e-mail: modeliho@kul.lublin.pl

${ }^{2}$ Department of Landscape Design, John Paul II Catholic University in Lublin, Konstantynów 1H, 20-708 Lublin, Poland; e-mail: hannakozak@kul.lublin.pl

${ }^{3}$ Department of Forest Management, University of Life Sciences in Poznan, Wojska Polskiego 71C, 60-625 Poznań, Poland; wegiel@au.poznan.pl
}

\begin{abstract}
Kozak I., Węgiel A., Strzeliński P., Frąk R., Stępień A., Kociuba P., Kozak H.: FORKOME model application for prognosis of forest fires. Ekológia (Bratislava), Vol. 33, No. 4, p. 391-400, 2014.

This paper presents the perspectives of FORKOME model use regarding the simulation of fire and its impact on forest stands. The calculation of probability of forest fires and predicting its effect on forest stands are analysed as well. The model is supposed to examine the impact of fires on pine stands, which ultimately leads to a decline in the viability of those trees. As a result of fire activity, there were determined the following categories of trees - undamaged, slightly damaged, heavily damaged and destroyed. Moreover, by conducting simulations on forests with Scots pine (Pinus sylvestris $\mathrm{L}$.), there were demonstrated the possibilities of FORKOME model practical application. Simulation shows the possibility of the model to predict the fire damage in a particular year and the perspective of a stand development, taking into account climate change and its influence on the frequency of fires. Prospects and directions of further developments of the model concerning simulation of fire in forest stands were discussed as well.
\end{abstract}

Key words: tree, simulation, fire damage, climate changes.

\section{Introduction}

In boreal forests, fire is the most important disturbance agent that shapes the structural, compositional and functional diversity of these ecosystems in natural landscape dynamic (Linder et al., 1997; Hunter, 1993).

A special category of models, called landscape fire succession models (LFSMs), has been applied to a spectrum of problems based on a variety of conceptual approaches and a wide range of solution techniques (Keane, 2004). The diversity of these models has created its own problems, including difficulties in comparing results among different ecosystem types and disturbance regimes, as well as the selection of the most appropriate model to use in a new geographical area or landscape setting. The diversity of models and their applications also hinders a decision on which landscape and ecosystem process, along with the level of par- 
ticularity used to represent them, is the most suitable for comprehending fire effects.

Therefore, it would be useful to rely on FORKOME model validation, performed on basis of data from Helgedomen Nature Reserve (HNR), in order to predict (with a certain probability) fire outbreaks (Kozak et al., 2012). There are two aspects related to that issue. The first one is the prediction of the fire outbreak, which in FORKOME model depends on temperature and precipitation factors while the second aspect is an estimation of losses in stands, which were caused by the fire.

On the basis of empirical data, the prediction of stand development, while taking into account aforementioned aspects, is extremely difficult to conduct (Pennanen, Kuuluvainen, 2002). Therefore, a computer model, which was created for particular conditions, can be applied in this type of analysis. Such a model can predict structure of stands as well as prevailing relations and connections in a particular stand. Such a model would allow for an early warning about the high probability of a fire and consequently would assess the potential damage. The model, therefore, would enable to carry out specific preventive activity in order to reduce the risk of natural disasters. With the use of prescribed burning simulation, for instance demonstrated in FORKOME model, is it possible to provide a more effective regeneration of Scots pine (Pinus sylvestris L.). Meanwhile, the implementation of empirical results to the model will increase the potential of its practical application, especially in prescribed burning scenario. The following notion was also confirmed by empirical enhancement of Scots pine regeneration in Scotland (Hancock et al., 2009).

The FORKOME model (Kozak et al., 2007, 2012), which contains elements of both ecological and growth yield strategy, has been specially designed for Swedish conditions (Kozak et al., 2012). The article presents the results of FORKOME model validation, conducted with the use of historical data from the HNR in Sweden on mixed stands with pine and consequently was used to prognosticate the future role of Scots pine (Pinus sylvestris L.), taking into account fire factor.

The purpose of this article is to demonstrate, by applying FORKOME model, the results of fire outbreak prognosis, which mainly depends on temperature and precipitation conditions, as well as to estimate the losses in the stand that the fire provokes.

\section{Material and methods}

The study site of HNR is located in the south-central part of Sweden (40 km to the north from Orebro). It has been a protected area since 1937, as an, especially, designed set-aside area located within intensively managed forest area owned by the state. In 1996, it was transformed to a reserve with the main purpose of conserving the dominating old pine stand, with long temporal continuity.

The area of HNR is 26 ha and consists of forest (about 10 ha) and mires (about 16 ha). In this study we analysed, with the use of the FORKOME model plots, forest stands of the reserve located on mineral soil (stands No. 28-31, $33,35,36,38,56,57,58-60,61,63$ ). Within each of the 15 analysed stands, up to 4 sample plots (each of $25 \times 25 \mathrm{~m}$ in size) were examined. In each plot all living trees, snags, stumps and logs with a diameter larger than $4 \mathrm{~cm}$ were measured and mapped. The height of all living trees was measured as well. Seedlings, defined as tree specimens of between 0.1 and $1.3 \mathrm{~m}$ in height, were also mapped. Soil depth, texture and moisture conditions, existence of subsurface water flow and ground vegetation types were analysed for every individual plot. The data taken from each of those plots regarding DBH (diameter at breast height), height and crown projection of each living tree was applied to initialise the simulation, parameter estimation and model calibration.

The FORKOME computer model belongs to the same type of gap models as JABOWA (Botkin et al., 1972), JA- 
BOWA 3 (Botkin, 1993) and FORET (Shugart, West, 1977; Shugart, 1984) models. Because, this model was already analysed in details in previous publications (Kozak, Menshutkin, 2002; Kozak et al., 2003, 2007, 2012), only a brief description of the model regarding the fire agent is required here.

In its current version, the FORKOME model (written in DELPHI language) contains also a recently introduced fire block. As a result, it is possible to simulate potential changes caused by its activity and finally predicted through simulation the impact of fires on forest conditions and stand regeneration. The predicted impact of fire is based on $\mathrm{DBH}$, height of flames, wind velocity, temperature, fire intensity and the degree to which trees are mineralised. It relates to the trees, understory and forest floor (Sidoroff et al., 2007).

Temperature and precipitation play a fundamental role in determining the level of fire risk. Therefore, the algorithm predicting the outbreak of forest fire was based on the activity of the blocks TEMP and PRECIP. In FORKOME model, in order to determine the probability of fire outbreak on the analysed area, there were used the upper and lower limits for both the annual total temperature $\left(D G D_{\max }, D G D_{\min }\right)$, as well as for the annual total precipitation $\left(P R E C I P_{\max }\right.$ PRECIP $\left.{ }_{\min }\right)$. The introduction of these limit values allowed for distinguishing different types of climate, out of which a key role was played by the extreme scenarios: cold - wet and hot - dry. The exact values of $D G D_{\text {max }}, D G D_{\min }, P R E C I P_{\max }, P R E C I P_{\min }$ can be entered by the user of the programme.

The model assumes that the risk of fire is very low $(P=0.01)$ if the climate in the $i$ th year of the simulation is cool and wet, therefore the assumption is fulfilled:

$$
D G D_{i}<D G D_{\min } \wedge \text { PRECIP }{ }_{i}>\text { PRECIP }_{\text {max }}
$$

Similarly, the risk of fire is very high $(P=0.99)$ if the climate in the $i$ th year of the simulation is hot and dry, therefore the assumption is fulfilled:

$$
D G D_{i}>D G D_{\max } \wedge P R E C I P_{i}<P R E C I P_{\text {min }}
$$

Thus, in each of the extreme scenarios an element of uncertainty is assumed, because for instance even in the hottest and driest climate conditions, forest fires may not occur.

In other cases, it is assumed that the probability of fire is expressed by the equation:

$$
P=\left\{\begin{array}{l}
0,01 \text { for } x \in[0 ; 0,01) \\
x \text { for } x \in[0,01 ; 0,99] \\
0,99 \text { for } x \in(0,99 ; 1]
\end{array}\right.
$$

Consequently, the main factor that determines the value of $P$ is $x$, which is expressed by various values, depending on the case concerned $(2,3,4)$, however it always accepts a value from 0 to 1 . Therefore, there were carried out modifications to the result of probability of forest fire $P$, so that its values were always contained in between 0.01 and 0.99 , because these are values of probability limits adopted in the model.

The most complex is the situation when $D G D$ and precipitation in the year $i$ of the simulation are among values of limits:

$$
D G D_{\text {min }} \leq D G D_{i} \leq D G D_{\text {max }} \wedge P R E C I P_{\text {min }} \leq P R E C I P_{i} \leq P R E C I P_{\text {max }}
$$

Then we assume that the coefficient of $x$ is given by the equation:

$$
x=a \cdot \frac{D G D_{i}-D G D_{\min }}{D G D_{\max }-D G D_{\min }}+b \cdot \frac{P R E C I P_{i}-P R E C I P_{\max }}{P R E C I P_{\min }-P R E C I P_{\max }}, a+b=1 \wedge a, b \in[0 ; 1]
$$

The probability of fire outbreak increases along with the increase in temperature and decrease in the amount of precipitation. In addition, in the formula (2) the coefficients of $a, b$ are determinant values that decide which of the factors (temperature or precipitation) is more significant on the particular area in terms of fire outbreak. These conditions may vary among different types of forest habitats, depending on their exact specificities. In order to determine that data, there is a need for an additional statistical analysis of empirical data. Therefore, the user can introduce his own parameters of $a, b$, according to the information from the analysed area. If there is no additional data and conducting the appropriate analysis is not possible, a default case is assumed, which equalises the effect of temperature and precipitation $(a=0.5, b=0.5)$.

There are still cases where one of the parameters $\left(D G D_{i}\right.$ or PRECIP) exceeds the limit values and the second parameter is between the limit values. Then, it is assumed that the effect of the exceeding parameter on the probability of fire outbreak amounts respectively to 0 or 1 , depending on whether the minimum value or the maximum one was exceeded: 


$$
\begin{aligned}
& \text { PRECIP }_{\min } \leq \text { PRECIP }_{i} \leq \text { PRECIP }_{\text {max }}: \\
& D G D_{i}<D G D_{\text {min }} \rightarrow x=b \cdot \frac{\text { PRECIP }_{i}-\text { PRECIP }_{\max }}{\text { PRECIP }_{\min }-\text { PRECIP }_{\max }}, b \in[0 ; 1] \\
& D G D_{i}>D G D_{\text {max }} \rightarrow x=a+b \cdot \frac{\text { PRECIP }_{i}-\text { PRECIP }_{\max }}{\text { PRECIP }_{\text {min }}-\text { PRECIP }_{\max }}, a+b=1 \wedge a, b \in[0 ; 1] \\
& D G D_{\min } \leq D G D_{i} \leq D G D_{\max }: \\
& \text { PRECIP }_{i}<\text { PRECIP }_{\text {min }} \rightarrow x=a \cdot \frac{D G D_{i}-D G D_{\text {min }}}{D G D_{\text {max }}-D G D_{\text {min }}}+b, a+b=1 \wedge a, b \in[0 ; 1] \\
& \text { PRECIP }_{i}>\text { PRECIP }_{\text {max }} \rightarrow x=a \cdot \frac{D G D_{i}-D G D_{\text {min }}}{D G D_{\text {max }}-D G D_{\text {min }}}, a \in[0 ; 1]
\end{aligned}
$$

If in a given year of the simulation the fire outbreaks in the stand, the main purpose is to determine the potential damage it may cause. The FORKOME model is based on a damage of an individual tree in the test stand $(S)$. In this regard, the logistic regression equation was used:

$$
S=\frac{1}{1+e^{-k}}
$$

Ratio $S$ has a value ranging from 0 to 1 , depending on the value of $k$. Factor $k$ is a function of several variables from the equation:

$$
k=B_{0}+B_{1} x_{1}+B_{2} x_{2}+\ldots+B_{n} x_{n}
$$

Equation (6) is an empirical model (linear regression), where the variables $x_{1}, \ldots, x_{n}$ are variables statistically significant for a specific tree damage caused by fire. In FORKOME model, the user can select elements available in the model (e.g. diameter at breast height, height, thickness of the cortex, etc.) and then enter the values of the corresponding coefficients $B_{0}, B_{1}, \ldots, B_{n}$, that are derived from the regression analysis previously conducted on the basis of empirical data. If the following analysis cannot be carried out, such an analysis is assumed by default coefficients, deduced on the basis of available literature, published data from the forests of southern Finland (Sidoroff et al., 2007). In this case, the following factors are relevant in terms of damage caused to the individual tree by the fire: diameter at breast height $(D B H[\mathrm{~cm}])$, bark thickness $(B T[\mathrm{~cm}])$ and the degree of tree trunks burns $(C S R)$ :

$$
\begin{aligned}
& k_{1}=1,52+19,075 \cdot C S R-0,281 \cdot D B H \\
& k_{2}=-3,325+18,675 \cdot C S R-3,307 \cdot B T
\end{aligned}
$$

Because both of these relations are statistically essential (Sidoroff et al., 2007), FORKOME model accepts the arithmetic average of the results as the default value:

$$
k=\frac{k_{1}+k_{2}}{2}
$$

The degree of trunk burns is a variable calculated from the approximate height of fire flames $\left(H_{f}\right)$ and wind velocity within the stand during the fire $\left(V_{W}\right)$ (Sidoroff et al., 2007):

$$
C S R=-0,04+0,082 \cdot H_{f}+0,042 \cdot V_{w}
$$

$H_{f}$ and $V_{w}$ parameters are defined in FORKOME model by a normal distribution, however their scope is inflicted by the user for both parameters that form the mean value and standard deviation.

Finally, for the scale of damage to a single tree $(S)$, FORKOME model provides the following interpretation:

$$
\begin{aligned}
& 0<S<0,25: \text { undamaged } \\
& 0,25 \leq S<0,5: \text { slightly damaged } \\
& 0,5 \leq S<0,75: \text { heavily damaged } \\
& 0,75 \leq S<1: \text { destroyed }
\end{aligned}
$$


In addition, when the tree is damaged $(12,13)$, FORKOME model allows for determining its degree of damage $(U)$ on the basis of the scale of damage (5) and provides the result in a percentage:

$$
U=\frac{S-0,25}{0,5} \cdot 100 \%, 0,25 \leq S<0,75
$$

It is assumed that a damaged tree grows slowly. As a consequence, in FORKOME model a specific tree growth is reduced, depending on the degree of the damage (15), in the course of 5 years since the fire outbreak. The probability of mortality for damaged trees increases as well.

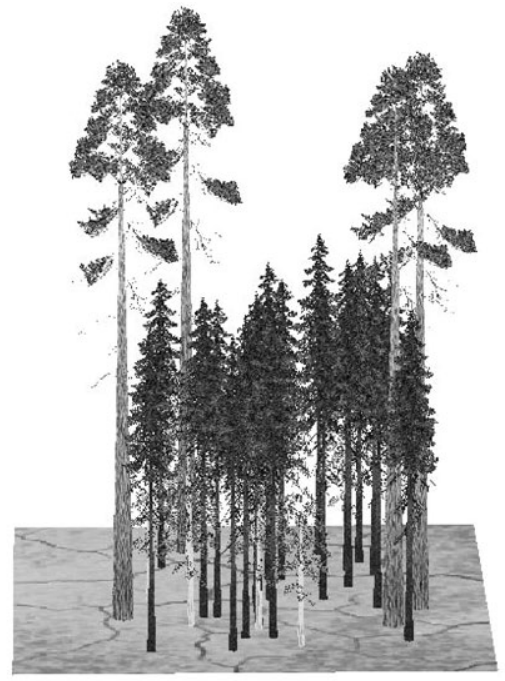

Fig. 1. The initial image of the area in FORKOME model simulation (before the simulation was conducted).

\begin{tabular}{|l|l|l|}
\hline Q. Area simulation results \\
\hline Year of simulatior \\
\hline Sum of the area & Acording to the species & Simple tree in the area \\
\hline Species & No of Individuals & Age \\
\hline Fagus silvatica & 0 & 0 \\
\hline Abies alba & 0 & 0 \\
\hline Picea abies & 28 & 19,3 \\
\hline Betula pendula & 8 & 12,6 \\
\hline Pinus sylvestris & 4 & 82,5 \\
\hline Acer pseudoplatanus & 0 & 0 \\
\hline Alnus incana & 0 & 0 \\
\hline Carpinus betulus & 0 & 0 \\
\hline Quercus petraea & 0 & 0 \\
\hline Fraxinus excelsior & 0 & 0 \\
\hline Larix decidua & 0 & 0 \\
\hline Populus tremula & 0 & 0 \\
\hline Quercus robur & 0 & 0 \\
\hline Tilia cordata & 0 & 0 \\
\hline
\end{tabular}

Fig. 2. The initial characteristic of trees from the area in FORKOME model simulation (before the simulation was conducted).

\section{Results}

Pine stands were used in order to verify the FORKOME model for the prognosis of the fire impact on forest areas. In FORKOME model there was presented one example (Fig. 1) of forest patch of sizes $25 \times 25 \mathrm{~m}$, that consisted of 40 trees (Fig. 2) belonging to three species: Pinus sylvestris, Picea abies and Betula pendula. What concerns the forest area, two simulations were conducted. In the first one, the model launched a simulation on forest fire in a particular year, while the second one provided a long-term prognosis taking into account only natural fires and different climate scenarios.

In FORKOME model it is possible to provoke a forest fire outbreak on selected parameters in a particular year of the simulation. Therefore, in order to verify the model, in the first year of simulation there was triggered a 'simulated controlled fire'. As parameters, there were adopted fire flames height of $H_{f}=1.5$ $\mathrm{m}$ with a standard deviation of $0.5 \mathrm{~m}$, and wind velocity of $V_{w}=5 \mathrm{~m} / \mathrm{s}$ with a standard deviation of $1 \mathrm{~m} / \mathrm{s}$.

Fire embraced mainly understory and forest floor. In the case concerned, the parameter limits of $D G D$ ${ }_{\text {min }}, D G D_{\max }, P R E C I P_{\min }, P R E C I P_{\max }$ were of no significance, because the probability of fire outbreak was of $100 \%$. The result of area conditions (after the fire outbreak) in the first year of simulation in FORKOME model is presented in Fig. 3.

It can be noticed that, due to the fire, there were damaged primarily the smallest trees, such as birch and spruce, what is a result of its low height (defined height of flames). In the final image, destroyed or heavily damaged (over 65\% damage) trees are presented as withered trees. Accurate simulation results 
can be seen on Fig. 3, where the characteristic of stand damage is shown. In that particular manner, it is possible to distinguish degree to which individual trees are damaged, and the number of trees that were completely destroyed by the fire.

Out of 40 trees existing originally in the beginning of simulation, only 26 of them (spruce and pine species) have survived the fire, while 22 out of those 26 belonged to spruce species and were heavily damaged. For instance, the damage degree of spruce ranged from $56 \%$ to $75 \%$. According to this percentage, it means that damaged trees are likely to die in the near future. The fire practically did not damage the four of the oldest pine trees (Fig. 4).

The accurate result of the simulation includes, among others a characteristic of damages of the stand, such as the parameters value that include: DEGDAY $=1375^{\circ} \mathrm{C}, \mathrm{PRECIP}=$ $500 \mathrm{~mm}$, fire probability $=1, \mathrm{CSR}=0.36$ and the number of trees destroyed by the fire.

In the case of long-term prognosis of stand growth, there should be taken into account an agent of natural forest fires, in order to set climate scenarios. It was assumed in the model that the simulation deals with changing climate conditions.

There was introduced a fixed scenario of a gradual transition of climate from warm and humid in the 0 year of the simulation $\left(\mathrm{DGD}_{0}\right.$ $=1500^{\circ} \mathrm{C}, \mathrm{PRECIP}_{0}=550 \mathrm{~mm}$ ) into warmer and drier during the entire simulation (Figs $5,6)$. Both the distribution of the annual total effective temperature (DGD) for the growing season, as well as the annual amount of precipitation in each year of the simulation was generated stochastically according to a normal distribution, with the mean and standard deviation entered by the user. Moreover, the model permits the user to introduce a trend of changes, by gradually increasing or decreasing the mean value parameter in a particular period of time. Fire parameters have been set as in the previous case, when the fire was 'artificially' provoked. This was followed by the stand development prognosis during the period of 50 years.

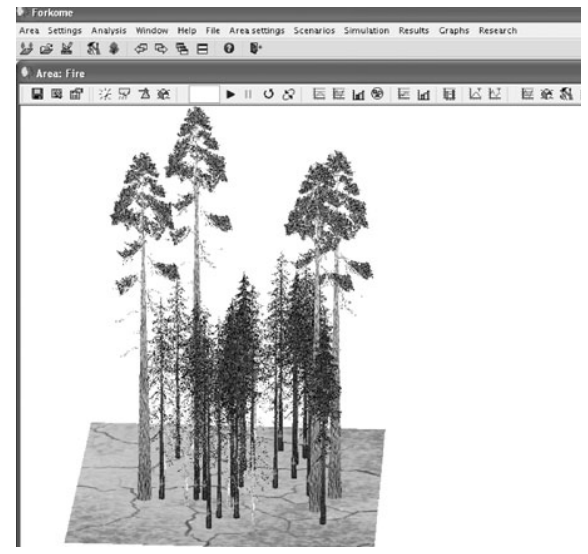

Fig. 3. The result image of the area in FORKOME model simulation (after the fire).

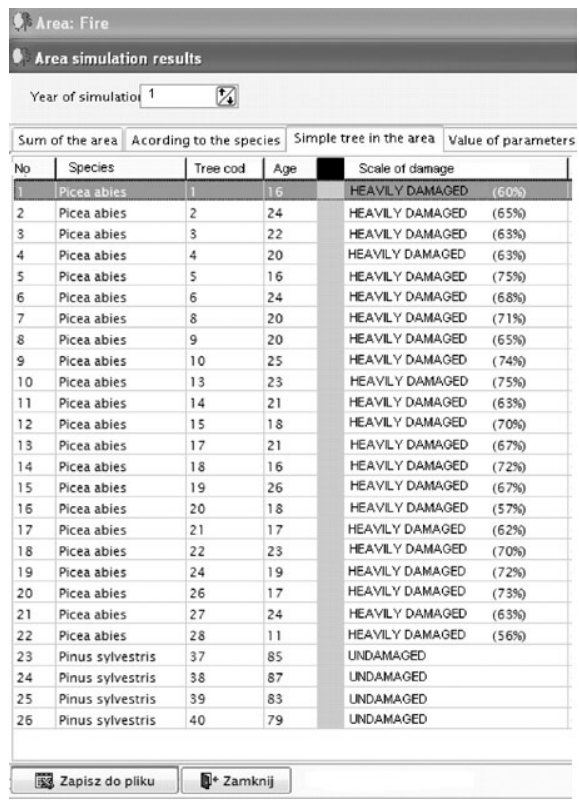

Fig. 4. Parameters of the stand in the first year of FORKOME model simulation (after the fire). 


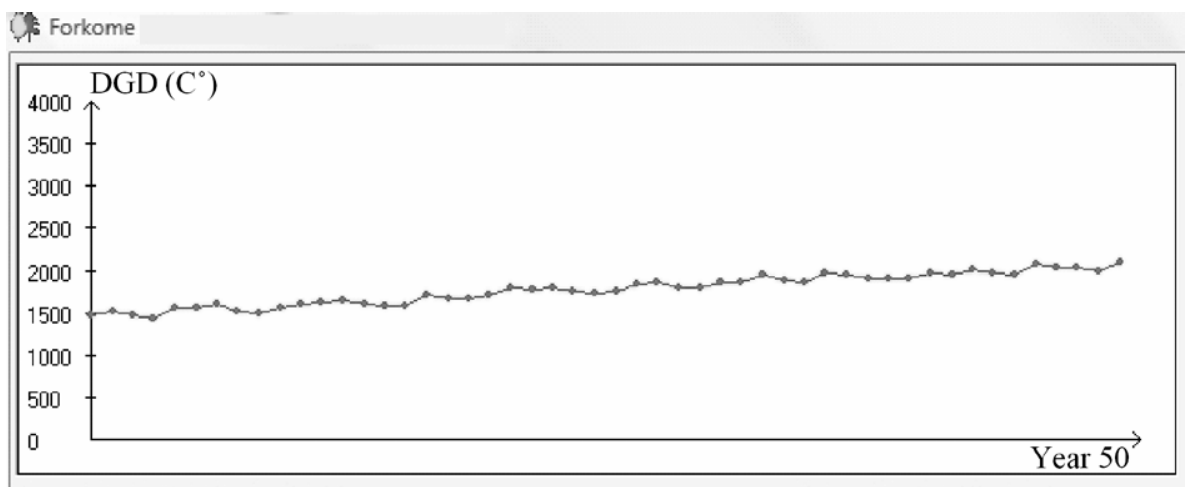

Fig. 5. Temperature changes scenario in the FORKOME model.

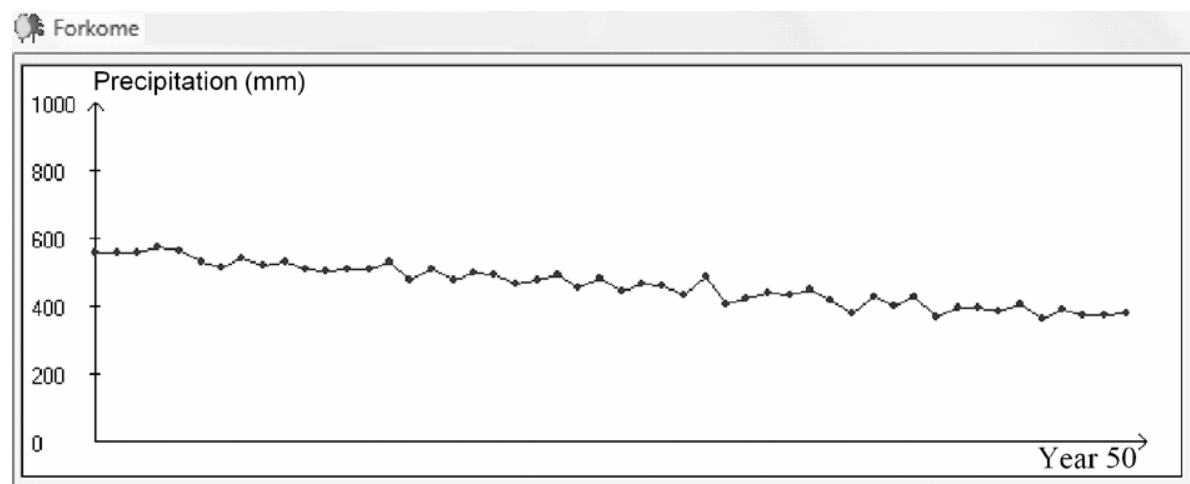

Fig. 6. Precipitation changes scenario in the FORKOME model.

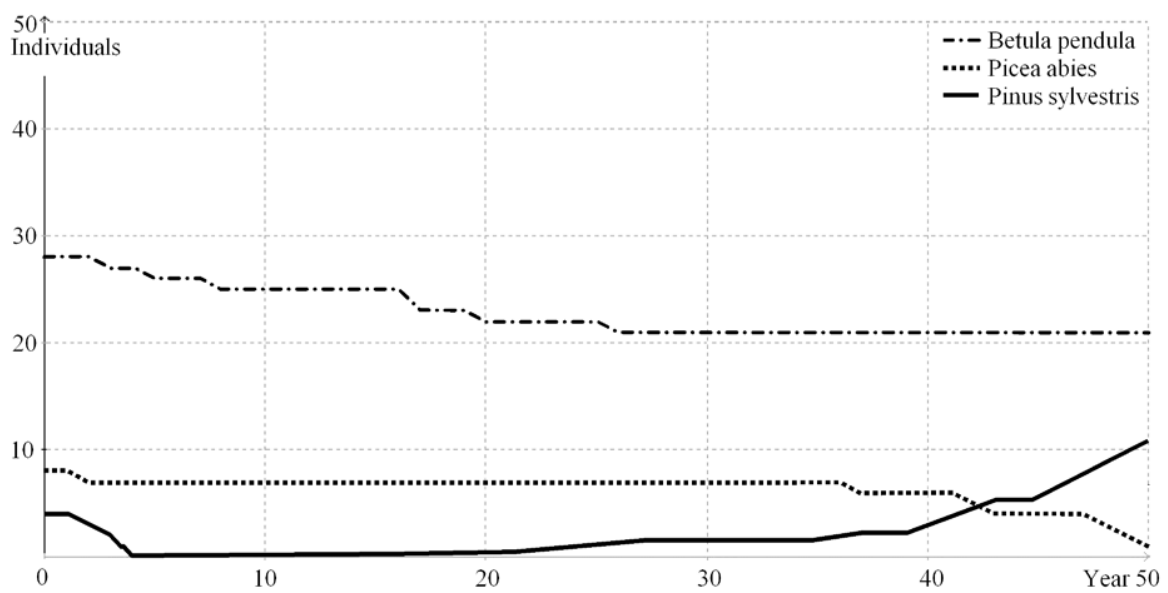

Fig. 7. Prediction of the number of trees in FORKOME model. 
The result of conducted simulations can be summarised by the following statements: (a) during the simulation of the next 50 years, forest fires occurred four times (years: 2, 16, 36, 47); (b) the simulation shows an increasing probability of fires, with about $37 \%$ at the beginning up to about $70 \%$ in the end; (c) fires outbreaks have negatively affected the number of trees, causing damage and weakening, and consequently the increased mortality of these trees may be noticed (Fig. 7).

Additionally, the application of FORKOME model in prescribe burning simulations predicted the increase in biomass and number of birch trees. However, what concerns pine species, its total biomass may increase up to $98 \mathrm{t} \cdot \mathrm{ha}^{-1}$.

\section{Discussion}

The article presents the perspectives for the application of FORKOME computer model in prognosis of the impact of natural disturbances on pine forests. The FORKOME model, in its latest version, includes a recently created and constantly developed block of forest fires. As a result, it is possible to simulate potential changes caused by fire activity, and thus predicted the impact of this disturbance agent on forest conditions and stand regeneration by conducting simulations on the issues concerned.

The FORKOME model predicted that the overall mortality of trees increases for younger individuals and decreases for those of greater size. This is a consequence of a decreased bark thickness and crown base height of species (Angelstam, Kuuluvainen 2004). Old trees with a thick bark usually survive fire, although damages caused by the fire are common as a result of cambium damage at the base of the trunk (Parviainen, 1996). The following conclusion confirms the experimental results of other authors (de Ronde, 1982; Swezy, Agee, 1991; Sidoroff et al., 2007).

The resulting scale of damage depends on fire and stand conditions, such as height of fire flames, type of tree wood (coniferous or deciduous), size of tree individuals and bark thickness. The result of the simulation (where despite of being heavily damaged, spruce individuals have survived) indicates the need for improving the current version of the FORKOME model, by adding a module which would enable simulating the dynamic of fire spreading.

The result of simulations shows that during the 50-years-simulation period forest fires occurred more often and that there exist an increased probability of fires, which have negatively affected the number of trees, causing their damage.

Based on a long-term simulations carried out in FORKOME model it can be concluded that the mortality of trees is caused by the fire, meaning that fire may severely damage its trunk (coefficient CSR). These damages do not destroy an individual tree immediately, however may contribute to its death within a few years after the fire occurred. This notion may be affirmed in the literature on the matter concerned (van Mantgem, Schwartz, 2004).

A severe damage caused to the crown layer by the fire may be also considered as an important cause of tree mortality (Peterson, Arbaugh, 1986; Ryan, Reinhardt, 1988). In FORKOME model simulation, the fire did not damage the oldest pine trees. Analogical data was elaborated on the territory of central Siberia (Wirth et al., 1999), where it was found that fire caused death of all 18 -year-old trees $(\mathrm{DBH}<10 \mathrm{~cm})$, nevertheless none of the individual trees in a contiguous 235-year-old stand (DBH range of 10-50 cm) died. Wirth et al. (1999) 
concluded that trees younger than the age of 20 die due to any fire, while a selective mortality regards stands that are between the age of 20 and 100, without modifying its structure, and survival of trees is nearly complete in stands older than the age of 100 .

Trees damaged by the fire had alterations that were visible not only in a visual appearance but also in the values of biometrical and thermal parameters, in particular an increased degree of damage of a tree leads to a reduction in its needle mass (Kuzyk, 2012). Consequently, it is essential to develop a module that simulates the dynamic of fire spreading, taking into consideration different types of fires. In this case, FORKOME model can be of great use in a perspective of prognosis of prescribed burning in forest areas.

As a result, it is planned to modify the model parameters from a single stand cell into cells covering a large area of forest. The following alteration means a need in combing the FORKOME model with CELLAUT model, proceeding in accordance with the cellular automata theory (Kozak, Menshutkin, 2002). This will enable the prognosis of the manner in which the fire spreads over a large area of forest. In this regard, the application of FORKOME and CELLAUT models in the field of spatial planning may be considered as an example of this combination (Kozak, Menshutkin, 2002).

\section{Conclusion}

Changing climate phenomenon causes intensification of disaster occurrences in forest areas. Probability of fire outbreak will rise along with an increase in temperature and decrease in precipitation. Therefore, the recently generated disaster block in the FORKOME model is becoming ever more vital. The described approach allows for the evaluation of an approximate risk of damage to individual trees and the degree of damage to the stand, as a set of trees. Awareness of the damage risk to the individual stands will enable to undertake the precautionary measures and limit the impact of the disaster.

The recently developed FORKOME model has been so far successfully applied in various studies to simulate the growth of the stand. The current results are promising. Analysing the structure of tree damage caused by the fire finds its confirmation in the literature on stand fire.

FORKOME model can be applied, among others in order to estimate the risk of fire occurrence and to evaluate the effectiveness of the applicable fire protection in a particular forest area. In future, the model could be used in order to assess the resilience of complex stands in larger areas. It is particularly essential to implement the analysis of entire forests (with CELLAUT model) and dynamic simulation of the fire spreading process.

\section{Acknowledgements}

Authors would like to thank sincerely the Polish Ministry of Science and Higher Education for financing the project (Grant No. NN 309 014638).

\section{References}

Angelstam, P. \& Kuuluvainen T. (2004). Boreal forest disturbance regimes, successional dynamics and landscape structures-a European perspective. Ecol. Bull., 51, 117-136. 
Botkin, D.B. (1993). Forest dynamics: an ecological model. Oxford, New York: Oxford University Press.

Botkin, D.B., Janak, J.F. \& Wallis J.R. (1972). Some ecological consequences of a computer model of forest growth. J. Ecol., 60, 849-872. DOI: 10.2307/2258570.

de Ronde, C. (1982). The resistance of Pinus species to fire damage. South African Forestry Journal, 122, 22-27. DOI: 10.1080/00382167.1982.9628828.

Hancock, M.H., Summers, R.W., Amphlett, A. \& Willi J. (2009). Testing prescribed fire as a tool to promote Scots pine Pinus sylvestris regeneration. European Journal of Forest Research, 128, 319-333. DOI: 10.1007/s10342 009-0267-5.

Hunter, Jr. M.L. (1993). Natural fire regimes as spatial models for managing boreal forests. Biol. Conserv., 65, 115120. DOI: 10.1016/0006-3207(93)90440-C.

Keane, R.E., Cary, G.J, Davies, I.D., Flannigan, M.D., Gardner, R,H., Lavorel, S., Lenihan, J.M., Li, C. \& Rupp T.S. (2004). A classification of landscape fire succession models: spatial simulations of fire and vegetation dynamics. Ecol. Model., 179, 3-27. DOI: 10.1016/j.ecolmodel.2004.03.015.

Kozak, I. \& Menshutkin V. (2002). Investigation of landscape dynamics with use of GAP and Cellular Automata models (in Polish). Człowiek i Przyroda, 13-14, 81-92.

Kozak, I., Menshutkin, V., Ferchmin, M., Potaczała, G., Jóźwina, M., Kozak, O. \& Seńko Z. (2003). Pine forest prognosis with use of FORKOME model in the Kampinoski National Park (in Polish). Parki Narodowe i Rezerwaty Przyrody, 22, 483-497.

Kozak, I., Chłódek, D., Zawadzki, A., Kozak, H. \& Potaczała G. (2007). Simulation of spruce forest reconstruction in the Polish Bieszczady using the FORKOME model (in Polish). Leśne Prace Badawcze, 2, 7-26.

Kozak, I., Mikusiński, G, Stępień, A., Kozak, H. \& Frąk R. (2012). Modelling forest dynamics in a nature reserve: a case study from south-central Sweden. J. For. Sci., 58(10), 436-445.

Kuzyk, A.D. (2012). Effects of ground fires on pine plantations (in Ukrainian). Науковий вісник Національного лісотехнічного університету України, 22(7), 19-26.

Linder, P., Elfving, B. \& Zackrisson O. (1997). Stand structure and successional trends in virgin boreal forest reserves in Sweden. For. Ecol. Manag., 98, 17-33. DOI: 10.1016/S0378-1127(97)00076-5.

Parviainen, J. (1996). The impact of fire on Finnish forests in the past and today. In J.G. Goldammer \& V.V. Furyaev (Eds.), Fire in ecosystems of boreal eurasia (pp. 55-64). Dordrecht: Kluwer Academic Publishers.

Pennanen, J. \& Kuuluvainen T. (2002). A spatial simulation approach to natural forest landscape dynamics in boreal Fennoscandia. For. Ecol. Manag., 164, 157-175. DOI: 10.1016/S0378-1127(01)00608-9.

Peterson, D.L. \& Arbaugh, M.J. (1986). Postfire survival in Douglas-fir and lodgepole pine: Comparing the effects of crown and bole damage. Can. J. For. Res., 16, 1175-1179. DOI: 10.1139/x86-209.

Ryan, K.C. \& Reinhardt E.D. (1988). Predicting postfire mortality of seven conifers. Can. J. For. Res., 18, 1291-1297. DOI: $10.1139 / x 88-199$.

Shugart, H.H. \& West D.C. (1977). Development of an Appalachian deciduous forest model and its application to assessment of the impact of the chestnut blight. J. Environ. Manag., 5, 161-179.

Shugart, H.H. (1984). Theory of forests dynamics. New York: Springer.

Sidoroff, K., Kuuluvainen, T., Tanskanen, H. \& Vanha-Majamaa I. (2007). Tree mortality after low-intensity prescribed fires in managed Pinus sylvestris stands in southern Finland. Scand. J. For. Res., 22, 2-12. DOI: 10.1080/02827580500365935.

Swezy, M.D. \& Agee J.K. (1991). Prescribed-fire effects on fineroot and tree mortality in old-growth ponderosa pine. Can. J. For. Res., 21, 626-634. DOI: 10.1139/x91-086.

van Mantgem, P. \& Schwartz M. (2004). An experimental demonstration of stem damage as a predictor of firecaused mortality for ponderosa pine. Can. J. For. Res., 43, 1343-1347. DOI: 10.1139/X04-001.

Wirth, C., Schulze, E., Schulze, W., von Stunzner-Karbe, D., Ziegler, W., Miljukova, I., Sogatche, A., Varlagin, A., Panvyorov, M., Grigoriev, S., Kusnetzova, W., Siry, M., Hardes, G., Zimmermann, R. \& Vygodskaya N. (1999). Above-ground biomass and structure of pristine Siberian Scots pine forests as controlled by competition and fire. Oecologia, 121, 66-80. DOI: 10.1007/s004420050908. 